Folia Histórica del Nordeste, $\mathbf{N}^{\circ} 20$ (Resistencia, 2012) IIGHI, IH - CONICET, UNNE

\title{
LAS TENDENCIAS MÁS RECIENTES EN LA HISTORIOGRAFÍA POLÍTICA ARGENTINA DE LA SEGUNDA MITAD DEL SIGLO XX. UNA APROXIMACIÓN ${ }^{1}$
}

\author{
An approximation to the more recent tendencies in the argentinian political \\ historiography during the second half of the twentieth century
}

\section{María Estela Spinelli}

\section{Resumen:}

El artículo presenta un panorama de la historiografía política argentina de la segunda mitad del siglo XX, en su vertiente académica². Partimos del análisis de los cambios introducidos en la etapa de la transición democrática para llegar a las interpretaciones y debates más recientes. El objetivo es elaborar una explicación que toma en cuenta las transformaciones vinculadas tanto al contexto temporal, como a la dinámica interna de la comunidad profesional, tratando de repensar las continuidades y las rupturas en los distintos campos temáticos.

$$
<\text { Historiografía }><\text { política }><\text { transformaciones }><\text { interpretaciones }>
$$

\footnotetext{
Abstract:

This article presents a panorama of the argentinian political historiography during the second half of the twentieth century, in the academic tradition. The analysis focuses on the changes registered during the democratic transition and the more recent debates and interpretations on the topic. The purpose of this paper is to offer an explanation that includes the transformations related to the historical context and those related to the dynamics of the professional community considering the continuities and ruptures in the different thematic fields.

$<$ Historiography $><$ politics $><$ transformations $><$ interpretations $>$

${ }^{1}$ Una primera versión de este trabajo fue presentada en el Workshop Interuniveristario: Partidos Políticos y elecciones en espacios regionales y provinciales, IIGHI (CONICET- UNNE). Resistencia, 25 y 26 de noviembre de 2011.

${ }^{2}$ En el contexto actual, la explosión editorial y las interpretaciones políticas del pasado han producido múltiples historias. Nuestra perspectiva analítica no pretende dar cuenta de esa diversidad; se orienta sólo al abordaje de la producción proveniente de las Ciencias Sociales en el ámbito profesional, nacional e internacional.
} 


\section{Consideraciones iniciales}

Podemos convenir en que desde la década de 1980 la historiografía política en la Argentina, comenzó a transitar una etapa de revitalización y renovación. Esta se produjo en el contexto de creciente expansión de las Ciencias Sociales en el campo académico y de vigorización del debate intelectual y político que coincidió con la etapa de transición a la democracia, luego de los años de cerrazón y silencio de la última dictadura militar del siglo $\mathrm{XX}^{3}$. Ese nuevo punto de partida abrió una serie de interrogantes, planteos de problemas, de enfoques y de temas -el autoritarismo y la democracia, el militarismo, la ciudadanía, la violencia, la participación y la cultura políticas, los partidos políticos, el peso de las corporaciones, las relaciones oposición y gobiernos ${ }^{4}$ - con los que los investigadores revisitaron el proceso de la crisis política de la hasta entonces caracterizada como "Argentina conflictiva" . Esta ya para entonces había sido abonada por una serie de investigaciones y ensayos, Tulio Halperín Donghi (1964), José Luis de Imaz, (1964), Guillermo O`Donnell (1972) que inauguró la periodización del momento más álgido de la inestabilidad política (1955-66), o la explicación sobre la emergencia de los nuevos golpes militares en Argentina y Brasil, de José Nun (1967). Desde la Teoría de la Modernización, de la Dependencia o del Estructuralismo Marxista se habían elaborado en la década de 1960 y la década de 1970 las explicaciones académicas hasta entonces disponibles.

En el ámbito específico de la disciplina histórica, tras la búsqueda de expansión de la Historia Social, -en una historiografía nacional, salvo pocas excepciones, todavía dominada por los viejos criterios de enseñanza e investigación-, desde la décas de 1980 se dieron los primeros pasos en el proceso de ampliación del campo profesional ${ }^{6}$ que ya no se detendría. Visto en perspectiva, este estuvo caracterizado por la consolidación y expansión de grupos de investigación ya instalados, el Instituto Di Tella, el CEDES, el IDES, el PEHESA, CLACSO y FLACSO, entre otros, y por el establecimiento del diálogo e intercambio académico entre los centros de investigación de las universidades del país. La dinamización se manifestó a través de la organización de congresos y jornadas de dimensión nacional, de la formación profesional de post-grado, en el exterior y en el ámbito local. Después de treinta años hoy podemos observar que los criterios profesionales entonces establecidos se han extendido a buena parte de la comunidad

\footnotetext{
${ }^{3}$ Sobre la cuestión hemos incursionado, Spinelli, María Estela (2007) y (2008). En esta línea pueden verse también Hugo Biagini y otras (1992).

${ }^{4}$ Los trabajos emblemáticos de esa etapa centrados en el debate sobre la transición democrática en la Argentina fueron Guillermo O`Donnell (1983), Marcelo Cavarozzi (1983), Peter Waldman y Ernesto Garzòn Valdèz (compiladores) (1983) y otros, que desde temprano ampliaron el campo de investigación ubicando la política en el centro del análisis

${ }^{5}$ Ese era el título de la compilación que dirigió Juan Francisco Marsal (1972), que reunió seis estudios sobre "problemas sociales argentinos" que abordaron "la desigualdad educacional en la Argentina", "La estructura Agraria y tipos de organización y acción campesina, "La estratificación social y su evolución histórica en Argentina", "La ideología de la derecha", "Los conflictos políticos de la Argentina Posperonista" y la "morfología y comportamiento de la opinión pública urbana argentina".

${ }^{6}$ Un panorama del estado de los estudios históricos en la Argentina en la primera mitad de década de 1980, en Tulio Halperìn Donghi (1986) y Luis Alberto Romero (1996).
} 
académica: se crearon numerosas Revistas Académicas que editan los centros de las distintas universidades, ha crecido el número de estudiantes y de profesionales de la Historia, se ha generalizado el intercambio de profesores y el campo de la investigación se ha tornado dinámico y productivo.

Por otra parte, debe señalarse que el marco de asociación de la historiografía política con las ciencias sociales y políticas, si bien permanece en franjas profesionales importantes, respecto al uso de sus teorías y modelos de análisis para pensar nuestros problemas, una conceptualización más precisa y otras herramientas que tomamos como préstamos, también aparece matizado o tiende a diluirse en campos específicos que abordan otros planos de la política que se alejan de las temáticas de la luchas por el poder y del conflicto entre sectores, o del clásico terreno de las políticas. Es también el caso de la historia de las ideas, los intelectuales, las culturas políticas, los grupos, los símbolos, las movilizaciones y múltiples manifestaciones culturales que la reflejan y que muestran en algunos casos otras influencias surgidas de la etapa que siguió al debate epistemológico sobre el "resurgimiento de la narrativa", entre nosotros desarrollado preponderantemente en la década de $1990^{7}$ y que dejó su impronta en la historiografía.

A partir de la década de 1990, donde por una parte concluyen buena parte de las investigaciones y discusiones abiertas en la década anterior, se amplía el campo editorial e ingresan también nuevas generaciones de profesionales, pueden señalarse nuevos matices y diálogos interdisplinares. La presencia de nuevos referentes teóricos en la construcción de explicaciones en Historia Política, Norbert Elías, Pierre Bourdie, Cliford Geertz, el Psicoanálisis.

Intentan fundarse nuevos campos con ambición de autonomía como la Historia Reciente que aborda los años del "Proceso" hasta las últimas presidencias constitucionales, del mismo modo que se discuten nuevas líneas interpretativas que se esfuerzan en replantear las ya hoy clásicas en diversos temas y problemas nacidas del impulso renovador y democratizador de la década de 1980, donde ocupa un lugar central la experiencia política del peronismo.

En suma, en este ampliado campo profesional, nutrido también por nuevas generaciones que buscan un lugar de expectación en la profesión, con estímulos e intereses diversos, la historia política no ha cesado de aumentar el número de sus cultores y temáticas.

\section{La tradición de la transición a la democracia}

El objetivo de este trabajo es presentar y poner en discusión la trayectoria de la historiografía política argentina abocada al estudio de la segunda mitad del siglo XX, desde la renovación teórica, metodológica y temática retomada a partir de la década de 1980, que imprimió nuevos caracteres al trabajo y a la dinámica de la vida académica y

\footnotetext{
${ }^{7}$ Sobre los distintos posicionamientos de historiadores sociales argentinos y latinoamericano frente al debate, Oscar Cornblit (compilador) (1992). Una interpretación sobre su impacto en la historiografía, en Carrizo de Muñoz, Nidia (2000)
} 
profesional. Nuestra intención es contemplar los derroteros que los viejos y los nuevos historiadores formados genéricamente en esos años fueron trazando a partir de los estímulos siempre cambiantes del contexto histórico político local y del mundial y de las novedades provenientes del campo disciplinar.

Si miramos nuestra experiencia profesional nacional, en el contexto más global de la disciplina histórica, para evaluar los ritmos siempre cambiantes del trabajo y la reflexión sobre el pasado, podemos considerar que la irrupción de la política como campo de estudio estaba presente en el campo historiográfico desde fines de los años sesentas y los tempranos setenta, cuando por ejemplo en la Escuela de los Annales comenzó a hablarse de una "nueva historia política" preocupada por el problema del poder, de los actores colectivos e individuales, tradicionales y modernos, de la prensa y los medios de comunicación, el análisis del discurso político y por fin del "retorno al

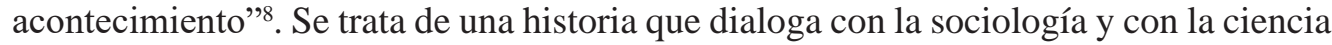
política, pero también con la Antropología y la Filosofía.

En la tradición anglosajona, sin presentarse como novedad, porque de hecho no lo era, ya que esa comunidad historiográfica nunca dejó de cultivar la historia política ${ }^{9}$, también se abrieron otros campos y perspectivas analíticas que abordaron nuevos aspectos de la política, los símbolos, las representaciones, el humor , las movilizaciones, en ese sentido varios de los artículos del viejo libro que compiló Lewis P. Curtis (1970): El Taller del historiador que circuló en la Argentina hacia los ochentas, reflejan esa experiencia ${ }^{10}$

Desde nuestra perspectiva de análisis, la etapa de transición a la democracia en la Argentina que podemos ubicar en el lento deshielo de la dictadura militar y el retorno de la discusión política primero reducido a ámbitos intelectuales y políticos, muchos de los cuales se comprometieron activamente en el proyecto democratizador, luego con un espacio creciente en los medios y en los círculos académicos, constituyo un punto de inflexión, como reflejaron, entre otras, las investigaciones de Cecilia Lesgart, que abordó el estudio de los intelectuales de izquierda y su punto de encuentro con los aportes a las teorías del autoritarismo, la democracia y la transición provenientes de las ciencias políticas, y de Nora Pagano, centrada en el análisis de las condiciones políticas creadas por la última dictadura y en los subterfugios hallados por los intelectuales que iniciaron la resistencia cultural y una renovación teórica y conceptual ${ }^{11}$. En este contexto la Historia Política se instala en nuestro medio académico, liderada ahora, no ya por el historicismo todavía vigente en amplios espacios de la comunidad de los historiadores que había animado el debate entre la tradición liberal-democrática preponderante en la Academia Nacional de la Historia y las diversas vertientes revisionistas nacionalistas, populistas y de izquierda, las más exitosas en el campo de la divulgación histórica ${ }^{12}$,

\footnotetext{
8 Jacques Julliard (1979), Pierre Nora (1979).

${ }^{9}$ Puede verse Peter Burke (1985)

${ }^{10}$ Lewis P. Curtis (1986).

${ }^{11}$ Cecilia Lesgart (2002) y (2004). Nora Pagano (2004)

${ }^{12}$ Alejandro Cattaruzza (2003)
} 
sino por aquella camada de los iniciadores de la Sociología y la Historia Social entre nosotros, Gino Germani, José Luis Romero, Tulio Halperín Donghi, Torcuato y Guido Di Tella, Juan Carlos Portantiero, Silvia Sigal, Ezequiel Gallo, y otros, desde fines de la década de 1950 y en los sesentas ${ }^{13}$. Ahora se hallaban acompañados por discípulos y nuevos profesionales que se sumergían en el terreno de la política, estimulados también por el contexto de la recuperación democrática y la revalorización de las prácticas políticas.

Respecto de la historiografía política que arbitrariamente aquí denomino de la segunda mitad del siglo XX, aunque en ella se incluye la experiencia del peronismo clásico que concitó y concita el mayor número de investigaciones y debates, podemos ver un nuevo punto de partida en la década del 80. Como dato importante, recordemos que el peronismo había resultado por primera vez derrotado en una elección limpia, lo cual se convirtió en un nuevo disparador de interrogantes políticos e intelectuales. Y efectivamente desde distintos ángulos el peronismo de sus años en el poder, de los de su expulsión de la legalidad y los de su retorno al gobierno en 1973, fue una cantera inagotable de preguntas y de confrontaciones interpretativas. En primer lugar no solo comienza a mirárselo en tanto régimen político ${ }^{14}$-desde las categorías analíticas de democracia y del autoritarismo- a explorarse mucho más detenidamente sus relaciones políticas en diversos planos, con la Iglesia, ${ }^{15}$ con el sindicalismo ${ }^{16}$, con los partidos políticos $^{17}$ y su cultura política donde sobresalieron las celebraciones, la propaganda, las fiestas y el discurso político ${ }^{18}$, sino que hacia adelante y hacia atrás se siguió considerando como el parte aguas del proceso político argentino del siglo $\mathrm{XX}^{19}$, viendo no sólo la década de los ' 30 como etapa preparatoria ${ }^{20}$, sino las diversas experiencias políticas que siguieron a su derrocamiento de 1955, como "post-peronismo".

${ }^{13}$ Las primeras incursiones historiográficas en la temática datan de los tempranos años ' 90 , cuando empezamos a buscar las raíces de la modernización historiográfica. Al respecto puede verse Fernando Devoto (compilador) (1994).

${ }^{14}$ Alberto Ciria (1983), Ricardo del Barco (1983) Mariano Plotkin (1993).

${ }^{15}$ Los estudios de los sesentas y setentas se habían centrado fundamentalmente en la relación del peronismo con el movimiento obrero, que contenía también la discusión de los "orígenes" que siguió durante unos años más, mientras que a partir de los ochenta las relaciones con la Iglesia ocuparon un rol central, José Oscar Frigerio (1990), Lila Caimari (1995) Susana Bianchi (2003).

${ }^{16}$ Los trabajos de Walter Litlle (1979) y de Louisse Doyon (1975), (1977) y (1984), publicados en la revista Desarrollo Económico habían iluminado la dinámica de los conflictos del movimiento obrero con el gobierno de Perón, mientras los de Hugo del Campo (1983), Ricardo Gaudio y Jorge Pilone (1983) buscaron las explicaciones de la asociación inicial que completaron los aportes de Juan Carlos Torre (1991).

${ }^{17}$ César Tcach (1991)

${ }^{18}$ Entre los que pueden mencionarse los libros de Emilio de Ipola (1985) y de Eliseo Verón y Silvia Sigal (1987).

${ }^{19}$ Recordemos el viejo libro de Alberto Ciria (1963) cuya periodización fue 1930-1946, o José Luis Romero (1965).

${ }^{20}$ Loris Zanatta (1996) y (2000). Un análisis historiográfico sobre las interpretaciones en torno a los años treinta, en Darío Macor (2005) Véase especialmente el primer capítulo: "Primeras imágenes del naufragio", pp. 9 a 80. 
Esta etapa fue un terreno de conocimiento compartido con los profesionales de las otras Ciencias Sociales que en muchos temas y problemas abrieron el camino apuntando a explicar procesos de más largo plazo, como la inestabilidad política, la tensión democracia-autoritarismo, o el Estado Burocrático-autoritario y podemos decir que los historiadores llegamos más tarde al estudio de esos períodos, con relevamientos empíricos más acotados que se inscribieron o se inspiraron en esos marcos conceptuales y problemáticos. Uno de los primeros ejes que se retomaron, fue el del sindicalismo y el movimiento obrero en relación con el peronismo, desde la emergencia de la pérdida del poder por parte de Perón hasta su recuperación del gobierno ${ }^{21}$. Un lugar importante tuvo y tiene también la cultura política de las izquierdas y su punto de encuentro con el peronismo ${ }^{22}$, cuyos primeros acercamientos dejaban ver un perfil cercano a lo autobiográfico, del mismo modo que las historias de las ideas y de los intelectuales. Se abrieron nuevos campos de estudio, las revistas ${ }^{23}$, la violencia ${ }^{24}$, la resistencia peronista ${ }^{25}$ los grandes estallidos sociales de fines de los años sesentas ${ }^{26}$, que tenían antecedentes en investigaciones y ensayos provenientes de sus contemporáneos. El peronismo como eje del conflicto político $1955-1973^{27}$ y el antiperonismo, durante el peronismo y durante la Revolución Libertadora ${ }^{28}$, o los abordajes sobre las gestiones presidenciales constitucionales de Arturo Frondizi y de Arturo Illia ${ }^{29}$, que en buena medida rompieron con el viejo esquema de las realizaciones de sus gobiernos para penetrar en los conflictos y en los problemas de poder con otros actores políticos. Desde similar perspectiva se abordaron las presidencias militares de la Revolución Argentina, hasta el segundo peronismo ${ }^{30}$, las organizaciones políticos militares ${ }^{31}$ y por fin el "proceso" 32 comenzaron a ser gradualmente abordados desde el punto de vista del método de la reflexión histórica.

\footnotetext{
${ }^{21}$ Marcelo Cavarozzi (1984), Juan Carlos Torre (1983). Enfoques que se vieron ampliados con la edición de la investigación de Daniel James (1988)

22 Oscar Terán(1991), Beatriz Sarlo (2001), Carlos Altamirano (2001), Silvia Sigal (1991) .

${ }^{23}$ Entre las revistas de gran circulación, las privilegiadas fueron Qué sucedió en 7 días y Primera Plana, la primera como depositaria del proyecto desarrollista y difusora de la alianza con el peronismo, la segunda mirada desde su actitud golpista frente a la experiencia democratizadora del gobierno de Illia. Un espacio importante tuvieron las revistas culturales más cercanas al proceso de radicalización de los sectores medios universitarios: Contorno, El escarabajo de oro, Los Libros, entre otras.

${ }^{24}$ Exploración iniciada por la historiadora María Matilde Ollier, en su tesis doctoral dirigida por Guillermo O’Donnell.

${ }^{25}$ Samuel Amaral, (1993), Ernesto Salas (1993) y la investigación de Julio Melón Pirro (2010) que concluyó años más tarde.

${ }^{26}$ Mónica Gordillo (1999), James P. Brennan (1994).

${ }^{27}$ Samuel Amaral y Mariano Ben Plotkin (1993).

${ }^{28}$ Marcela García Sebastián (1999) y María Estela Spinelli (2005).

${ }^{29}$ Daniel Rodríguez Lamas (1983) y (1985), Catalina Smulovitz (1988), Celia Szusterman (1998). En los últimos años, se editó el libro de César Tcach y Celso Rodríguez (2009).

${ }^{30}$ Desde temprano en él incursionaron, entre otros Guillermo O’Donnell (1983), Rubén Perina (1984), siguieron casi inmediatamente, Liliana de Riz (1983), Guido Di Tella (1983), Victoria Itzcovitz (1985).

${ }^{31}$ Richard Gillespie (1982), Lucas Lanusse (2005), Victoria Itzcovitz (1983).

32 Cuya primer indagación empírica rigurosa y abarcativa fue la de Marcos Novaro y Vicente Palermo (2003).
} 


\section{Nuevas incursiones sobre la misma agenda}

Básicamente los temas instalados en la década de 1980, que como señalamos, hundían sus raíces en los análisis de los politólogos y sociólogos en las décadas de 1960 y 1970, siguieron constituyendo los puntos interés y de debate entre los historiadores que incursionaron en este período. Las investigaciones se ampliaron a campos más específicos, sobre todo en el estudio de las izquierdas, donde se exploraron las trayectorias de grupos ideológico-políticos, de sus partidos, el surgimiento de la nueva izquierda ${ }^{33}$, la crisis y la renovación del catolicismo ${ }^{34}$ y las organizaciones internas del peronismo a derecha e izquierda ${ }^{35}$, y de las derechas específicamente. Se analizaron los fenómenos de la radicalización y luego el de la democratización de los cuadros revolucionarios $^{36}$, como así también la experiencia de la dictadura ${ }^{37}$ y de la etapa democrática proyectándose casi hacia nuestros días. La historia política se hace más empírica, aún cuando el terreno de estudio sigue siendo compartido con las otras ciencias sociales que le dan matices específicos y surgen las primeras discusiones sobre la especificidad y los rasgos propios de la que primero se dio en llamar Historia del Presente, que luego se redefine como Historia Reciente ${ }^{38}$.

Un terreno en el que se dieron sustantivos avances desde los años noventa en adelante, es el referido a las dimensiones provinciales y locales de la política, que comenzaron aisladamente en grupos de investigación de algunas de las más dinámicas y consolidadas universidades del interior, Córdoba, Santa Fe, Rosario, Mar del Plata, del Centro de la Provincia de Buenos Aires, Comahue, por mencionar algunas, a las que se fueron sumando rápidamente casi todas las demás. Desde exploraciones provinciales, locales o regionales de la política, los historiadores comenzaron a discutir procesos, trayectorias y configuraciones partidarias particulares, el primer ejemplo exitoso de esta experiencia, fue la compilación dirigida por Darío Macor y César Tcach: La invención del peronismo en el interior del país que editó la Universidad del Litoral, en 2003. Este reunió estudios sobre Córdoba, Santa Fe, Jujuy, Salta, Tucumán, Mendoza, Río Negro, Neuquén y Santa Cruz sobre distintos aspectos del surgimiento del peronismo en esas provincias. Esa experiencia gestada en diversos encuentros, jornadas y simposios, fue seguida por similares emprendimientos ${ }^{39}$ que hoy constituyen un núcleo de estudios sobre el peronismo, con entidad y organización propia. Quizás sea este uno de los planos en el que puede vislumbrarse muy claramente la integración de una comunidad historiográfica que reúne a los investigadores del conjunto del país.

\footnotetext{
${ }^{33}$ En este plano se destacan las investigaciones de Raúl Burgos (2004) y Cristina Tortti (2009).

${ }^{34}$ Inicialmente explorado por Loris Zanatta en el libro en coautoría con Roberto Distéfano (2004), Eduardo Zanca (2006).

${ }^{35}$ Humberto Cucchetti (2010), Vera Carnovale (2011).

${ }^{36}$ Ejemplo de ello son los dos libros de María Matilde Ollier (1998) y (2009).

${ }^{37}$ La colección de Historia Argentina de Paidós, incorpora dos nuevos volúmenes, el de Liliana De Riz (2001) y el de Novaro y Palermo (2003).

${ }^{38}$ Una reflexión sobre sus particularidades aparece esbozada en la presentación del libro de Marcos Novaro (2006), Marina Franco y Florencia Levín (2009).

${ }^{39}$ Oscar Aelo, compilador (2011).
} 
A pesar de los vaivenes políticos que constituyen la historia externa de la disciplina y la permean, la continuidad institucional explica que buena parte de los proyectos de investigación, de renovación académica y de los proyectos editoriales que marcaron la agenda temática y problemática de los ochenta se proyectaron y se ampliaron en las décadas siguientes. Surgen nuevas síntesis históricas del siglo XX, la Breve Historia Contemporánea de la Argentina de Luis Alberto Romero, la Historia Social de la Argentina Contemporánea de Torcuato Di Tella, o el ensayo intelectual totalizador de Tulio Halperín La larga agonía de la Argentina peronista. El panorama editorial se completa con colecciones de Historia General Argentina, producto de proyectos colectivos donde participan buena parte de los profesionales que animaron la década anterior y algunos más nuevos, como fue la Nueva Historia Argentina de Sudamericana que organizaron Juan Suriano y Mirta Lobato, o la Nueva Historia de la Nación Argentina, de la Academia Nacional de la Historia que también la mostraba ampliada y aggiornada, la Biblioteca del Pensamiento Argentino, todas ellas avanzaron hasta bien entrado el siglo XX. Se completaron también, los volúmenes que continuaron la vieja colección de la Historia Argentina de Editorial Paidós, dirigida Por Tulio Halperín Donghi, hasta los tiempos más recientes.

Otro dato historiográfico vinculado a la preponderancia del interés por la política desde la restauración democrática, es lo que podríamos destacar como "el retorno de la biografía", género éste que no había sido mayormente cultivado, salvo por los historiadores formados en la tradición anterior y que se halla directamente vinculado a la revitalización de la historia política, por cuanto una de las primeras colecciones fue precisamente: Los nombres del poder. En ella, historiadores y sociólogos indagaron en la vida de personajes claves de la política argentina, Sarmiento, Pellegrini, Alvear, Justo, Perón, Sabattini, Frondizi.

En los últimos años comienza a ser visible también la presencia de una nueva generación de historiadores, al campo de la historiografía política de la segunda mitad del siglo XX, que transitoriamente apostamos a considerar en dos grandes líneas, una, que sobre todo después de la crisis de 2001, revisita historiográficamente los temas y cuestiones de la agenda de los ochentas, o aborda nuevos sujetos históricos, revisando y cuestionando el conocimiento heredado de la que ellos genéricamente llaman corriente socialdemócrata. Desde perspectivas que sin renegar de los cánones profesionales vigentes, postulan una serie de críticas al marco académico y a la tradición democrática hegemónica entonces renacida y a sus interpretaciones sobre los temas nodales, particularmente el peronismo, insistiendo en que el mismo debe ser "normalizado". Algunos de ellos recurren a los aportes teóricos de Ernesto Laclau respecto del populismo. Cultivan un discurso histórico en cierto modo áspero y hostil hacia los referentes intelectuales más destacados de las tradiciones académicas que venimos tratando, revisando las lecturas, las ideas y los valores entonces abandonados o que les eran ajenos a éstos en la coyuntura del renacimiento democrático, lo popular, lo marginal, o los historiadores y publicistas antiacadémicos de los sesentas-sesentas, buscando un nuevo compromiso con el presente. 
La otra línea que mencionamos, desde la perspectiva más estricta del conocimiento trabaja por fundar un campo autónomo, "la historia reciente". Campo que, como estudio del pasado cercano de la política, se convirtió en uno de los ejes privilegiados de análisis por parte de los intelectuales de las Ciencias Sociales que en los tempranos ochentas indagaron sobre el "Proceso de Reorganización Nacional", "El tercer gobierno peronista", o la "organización Montoneros", desde una perspectiva interdisciplinar de la que no estuvieron del todo ausentes los historiadores. Los nuevos aportes enfatizan también en el diálogo disciplinar y epistemológico y destacan los problemas específicos del tiempo y de las fuentes, orales y escritas, de la subjetividad y otros, en el pasado más cercano ${ }^{40}$.

\section{Síntesis y conclusiones}

Nuestro objetivo para esta somera revisión historiográfica, fue tomar en cuenta, el tiempo en que los historiadores y demás analistas sociales abordaron sus estudios sobre el proceso político de la segunda mitad del Siglo XX y las transformaciones en el campo disciplinar, internas e internacionales, con la intención de ensayar una explicación sobre el estado de estos estudios de la Historia Profesional en la Argentina.

Revisando tres trabajos sobre la Historia de la Historiografía en Francia y en los Estados Unidos, los de Gerard Noiriel (1997), de Peter Novick (1998) y en alguna medida el de Georg Iggers (1998) que inician su reflexión desde fines del siglo XX, a partir de la "crisis de la historia", podemos notar que algunos de esos rasgos, discusiones y tendencias del campo profesional son visibles en espacios gradualmente más amplios de nuestra comunidad académica. Para ello basta revisar el camino recorrido por nuestra historiografía entre el panorama presentado por Tulio Halperín en 1986 en aquel artículo de celebración de los 25 años de la revista Desarrollo Económico, que mostraba un panorama de la profesión y de la investigación muy desigual y fragmentado, donde coexistían un extendido historicismo de viejo cuño y unos acotados nichos de historiadores sociales formados en los cánones más modernos de la disciplina histórica que bregaban por imponer un nuevo perfil de docente-investigador, hasta los tiempos más recientes, visibles en algunos artículos de reflexión, como los de Luís Alberto Romero, sobre la formación de un nuevo campo profesional, o el contrapunto entre Roy Hora e Hilda Sábato sobre los rasgos dominantes de la historiografía hacia el año 2001.

Todavía con problemas, desbalances y retrasos encontramos un campo académico más consolidado o en vías de consolidación, considerablemente ampliado en número de profesionales de la Historia y extendido a la dimensión nacional de la investigación, donde la tesis se ha convertido en una exigencia profesional y el mapa del conocimiento también se ha extendido.

A tono con los desarrollos actuales de la disciplina en otras tradiciones historiográficas, también es visible la preocupación de los historiadores por incidir en

\footnotetext{
${ }^{40}$ Los historiadores franceses denominaron tempranamente a este campo "la historia política muy contemporánea".
} 
la opinión pública y por la divulgación del conocimiento histórico a un público lector mucho más amplio, en lo que se ha dado en llamar la "alta divulgación" cumpliendo el viejo precepto de la utilidad de la Historia de "ilustrar a los contemporáneos sobre el conocimiento del pasado".

Los historiadores, en general, y los de la historiografía, en particular, solemos ser más afectos a buscar las rupturas y los nuevos puntos de partida en el campo del conocimiento de la disciplina, que las continuidades y consolidaciones en las formas de trabajo y de pensamiento. Se habló de una vieja y de una nueva historia, que llevó a Peter Burke a preguntarse muy razonablemente, “¿Hasta qué punto es nueva la Nueva Historia? ${ }^{41}$, tendencia en la que, en cierto modo hemos caído al postular la renovación de la historia política a partir de los años ochenta, sin mirar detenidamente los puntos de continuidad en el planteo de los problemas formulados por los intelectuales de las décadas de los ' 60 y los '70, que fundaron entre nosotros el perfil interdisciplinario de las Ciencias Sociales ${ }^{42}$.

Pensando en el breve recorrido realizado en el curso de este esbozo de treinta años de historiografía política de la segunda mitad del siglo XX argentino podemos señalar que, si bien hoy encontramos un panorama que tiende a ser más homogéneo en el campo de la práctica histórica y una notable ampliación del campo profesional, las continuidades han sido por lo menos tan recurrentes como las rupturas.

\section{Referencias Bibliografica}

Aelo, Oscar (compilador). 2011. Las configuraciones provinciales del peronismo. Actores y prácticas políticas, 1945-1955, Instituto Cultural de la Provincia de Buenos Aires.

Amaral, Samuel. 1993. "El avión negro. Retórica y práctica de la violencia”, en Amaral Samuel y Mariano Ben Plotkin, Perón del exilio al poder, Buenos Aires, Cántaro.

Altamirano, Carlos. 2000. Bajo el signo de las masas, 1943-1973, Buenos Aires, Ariel. 2001. Peronismo y cultura de izquierda, Buenos Aires, Temas.

Biagini, Hugo, Hebe Clementi y Marilu Bou. 1992. La historiografía argentina: la década de 1980, Buenos Aires, Centro Editor de América Latina.

Bianchi, Susana. 2003. Catolicismo y peronismo, Buenos Aires, Prometeo.

Brennan, James P. 1996. El Cordobazo. Las guerras obreras en Córdoba, 1955-1976, Buenos Aires, Sudamericana, (1994).

Burgos, Raúl. 2004. Los Gramscianos argentinos, Buenos Aires, Siglo XXI.

Burke, Peter. 1985. "La historiografìa en Inglaterra desde la Segunda Guerra Mundial", en Actitudes, tendencias y problemas metodològicos, Universidad de Navarra (Actas de Congreso).

(ed.). 1993. Formas de hacer historia, Madrid, Alianza Universidad, (1991).

Caimari, Lila. 1995. Perón y la Iglesia Católica, Buenos Aires, Sudamericana.

Carnovale, Vera. 2011. Los combatientes. Historia del PRT-ERP, Buenos Aires, Siglo XXI.

Carrizo de Muñoz, Nidia. 2003. “Los caminos teóricos de la historiografía del 90. El mundo

\footnotetext{
${ }^{41}$ En Peter Burke (editor) (1993), capítulo 1: “Obertura: La nueva historia, su pasado y su futuro”, ver páginas 19 a 21.

${ }^{42}$ Dos artículos advirtieron sobre esos rasgos, Ezequiel Gallo y Carlos Floria (1988).
} 
real, la desmitificación y la racionalidad”, en Ciclos, 25/26, UBA-Fac. de Ciencias Económicas, pp 225 a 251.

Cavarozzi, Marcelo. 1983. Autoritarismo y Democracia en la Argentina (1955-1983), Buenos Aires, CEAL.

1984. Sindicatos y política en la Argentina, Buenos Aires, CEDES.

Cattaruzza, Alejandro. 2003. "El revisionismo: Itinerarios de cuatro décadas", en Alejandro Cattaruzza y Alejandro Eujanián. Políticas de la Historia, 1860-1960, Buenos AiresMadrid, Alianza, 2003, pp 103 a 182.

Ciria, Alberto. 1963. Partidos y poder en la Argentina Moderna Buenos Aires, de la Flor. 1983. Política y Cultura popular. La Argentina peronista 1946-1955, Buenos Aires, de la Flor.

Cornblit, Oscar (Compilador). 1992. Dilemas del conocimiento histórico: Argumentaciones y controversias, Buenos Aires, Sudamericana-Di Tella.

Cucchetti, Humberto. 2010. Combatientes de Perón, herederos de Cristo. Peronismo, religión secular y organizaciones de cuadros, Buenos Aires, Prometeo.

Curtis, Lewis P. (Editor). 1986. El Taller del historiador, México, Fondo de Cultura Económica, (1970).

De Ipola, Emilio. 1983. Ideología y discurso populista, Buenos Aires, Folios.

Del Barco, Ricardo. 1983. El Régimen Peronista, Buenos Aires, Editorial de Belgrano.

Del Campo, Hugo. 1983. Sindicalismo y peronismo. Los comienzos de un vínculo perdurable, Buenos Aires, FLACSO.

De Riz, Liliana. 1986. Retorno y derrumbe: el último gobierno peronista (1973-1976), Buenos Aires, Hyspamérica (1983).

-------------. 1994. La política en suspenso, 1966 1976, Buenos Aires, Paidós, 2001.

Devoto Fernando (compilador): La Historiografía Argentina en el siglo XX, (vol.II) Buenos Aires, Centro Editor de América Latina.

Distéfano, Roberto y Loris Zanatta. 2004. Historia del catolicismo en la Argentina, Buenos Aires, Sudamericana.

Di Tella, Guido. 1983. Perón-Perón, 1973-1976, Buenos Aires, Sudamericana-Di Tella.

Doyon, Louise. 1975. "El crecimiento sindical bajo el peronismo", en Desarrollo Econòmico $N^{a} 57$.

1977. "Conflictos obreros durante el régimen peronista (1946-1955), en Desarrollo Económico $\mathrm{N}^{\mathrm{a}} 67$.

1984. "La organización del movimiento sindical peronista, 1946-1955, en Desarrollo Económico, Na 94.

. 2006. Perón y los trabajadores. Los orígenes del sindicalismo peronista, 19431955, Buenos Aires, Siglo XXI Editora Iberoamenricana.

Floria, Carlos. 1988. “Apuntes sobre bibliografía histórico-política de la Argentina contemporánea", en capìtulo VII: Historiografía de la historia política de los siglos XIX y XX, de Historiografía Argentina 1958-1988. Una evaluación crítica de la producción histórica nacional, Comité Internacional de Ciencias Históricas. Comité Argentino, Buenos Aires, (Actas de las Segundas Jornadas del Comité Argentino del Comité Internacional de Ciencias Históricas Reunido en Paraná en Agosto de 1988).

Franco, Marina y Florencia Levín. 2009. La Historia Reciente, perspectivas y desafíos de un campo en construcción, Buenos Aires, Paidòs, 2009.

Frigerio, José Oscar. 1990. El síndrome de la Revolución Libertadora. La Iglesia contra el 
Justicialismo, Buenos Aires, Centro Editor de América Latina.

Gallo, Ezequiel. 1988. "Historiografía política (1880-1900)", en capítulo VII: Historiografía de la historia política de los siglos XIX y XX, de Historiografía Argentina 1958-1988. Una evaluación crítica de la producción histórica nacional, Comité Internacional de Ciencias Históricas. Comité Argentino, Buenos Aires. (Actas de las Segundas Jornadas del Comité Argentino del Comité Internacional de Ciencias Históricas Reunido en Paraná en Agosto de 1988).

García Sebastián, Marcela. 1997. La oposición política al peronismo. Los partidos en la Argentina entre 1943 y 1951, Tesis Doctoral, Universidad Complutense de Madrid (Instituto Universitario Ortega y Gasset), Madrid.

Gaudio Ricardo y Jorge Pilone. 1984. "Estado y relaciones laborales en el período previo al surgimiento del peronismo", en Desarrollo Económico Na 94.

Guillespie, Richard. 1982. Soldados de Perón. Los Montoneros, Buenos Aires, Grijalbo, 1987.

Gordillo, Mónica. 1999. Córdoba en los sesenta. La experiencia del sindicalismo combativo, Universidad de Córdoba, (segunda edición).

Halperín Donghi, Tulio. 1995. Argentina en el callejón, Buenos Aires, Ariel (1964).

1986. “Un cuarto de siglo de historiografía argentina (1960-1985), en Desarrollo Econòmico $N^{a} 100$.

Hora, Roy. 2001. "Dos décadas de historiografía argentina”, en Punto de vista 69, Buenos Aires.

Iggers, Georg. 1998. La ciencia histórica en el siglo XX. Las tendencias actuales, Barcelona, Idea Universitaria.

Imaz, José Luís de. 1964. Los que mandan, Buenos Aires, Eudeba.

Itzcovitz, Victoria. 1985. Estilo de gobierno y crisis política (1973-1976), Buenos Aires, Centro Editor de América Latina.

James, Daniel. 1988. Resistencia e integración. El peronismo y la clase trabajadora argentina (1946-1976), Buenos Aires, Sudamericana.

Julliard, Jacques. 1979. “La política” Págs. 237 a 257, Jacques Le Goff y Pierre Nora (Directores): Hacer la Historia, II. Nuevos enfoques, Barcelona Editorial Laia (1974).

Lanusse, Lucas. 2005. Montoneros. El mito de sus doce fundadores, Buenos Aires, Vergara.

Lesgart, Cecilia. 2002. "Usos de la transición a la democracia. Ensayo, ciencia y política en la década del ochenta", en Estudios Sociales, Universidad Nacional del Litoral.

izquierda intelectual argentina en hacia la democracia. Una tendencia de la izquierda intelectual argentina en el exilio mexicano", en Fernando Devoto y Nora Pagano (editores): La historiografía académica y la historiografía militante en Argentina y Uruguay, Buenos Aires, Biblos.

Little, Walter. 1979. "La organización obrera y el Estado peronista, 1943-1955”, en Desarrollo Económico N 75.

Macor Darío y César Tcach (Editores). 2003. La invención del peronismo en el interior del país, Santa Fe, Universidad Nacional del Litoral.

--------------. 2005. Nación y provincia en la crisis de los años treinta, Universidad Nacional del Litoral, Santa Fe.

Marsal, Juan Francisco. 1972. Argentina conflictiva. Seis estudios sobre problemas sociales argentinos, Buenos Aires, Paidós.

Melón Pirro, Julio César. 2010. El peronismo después del peronismo, Buenos Aires, Siglo XXI.

Noiriel, Gerard. 1997. Sobre la crisis de la Historia, Madrid, Ediciones Cátedra, Universitat de València. 
Nora, Pierre. 1979. "La vuelta al acontecimiento", en Jacques Le Goff y Pierre Nora (Directores): Hacer la Historia, volumen I: Nuevos Problemas, pp 21 a 239.

Novaro, Marcos y Vicente Palermo. 2003. La dictadura militar 1976/1983, del golpe de Estado a la restauración democrática, Buenos Aires, Paidós. Aires, Edhasa.

Novick, Peter. 1997. Ese noble sueño: La objetividad y la historia profesional norteamericana, México, Instituto Mora.

Nun, José. 1967. “América Latina: la crisis hegemónica y el golpe militar”, en Desarrollo Económico, $\mathrm{N}^{\mathrm{o}}$ 22-23.

Ollier, María Matilde. 1998. La creencia y la pasión. Privado, público y político en la izquierda revolucionaria, Buenos Aires, Ariel.

2009. De la revolución a la democracia. Cambios privados, públicos y políticos de la izquierda argentina, Buenos Aires, Siglo XXI editores.

Pagano, Nora. 2004. "Las ciencias sociales durante la dictadura argentina (1976-1981), en Fernando Devoto Nora Pagano (editores) La Historiografía Académica y la Historiografía militante en Argentina y Uruguay, Buenos Aires, Editorial Biblos.

Perina, Rubén. 1984. Onganía, Levington, Lanusse, Buenos Aires, Editorial de Belgrano.

Plotkin, Mariano. 1993. Mañana es San Perón, Buenos Aires, Ariel.

O’Donnell, Guillermo. 1972. Modernización y autoritarismo, Buenos Aires, Paidós.

1983. El Estado Burocrático-Autoritario, Buenos Aires, Editorial de Belgrano.

Rodríguez Lamas, Daniel. 1983. La presidencia de Frondizi, Buenos Aires, Centro Editor de América Latina. Latina, 1985.

Romero, José Luis. 1965. Partidos La Historia de las Ideas políticas en la Argentina, Buenos Aires, Fondo de Cultura Económica.

Romero, Luis Alberto: 1996. "La Historiografía argentina en la democracia: los problemas de la construcción de un campo profesional”, en Entrepasados № 10, Buenos Aires.

Sábato, Hilda. 2001. "La historia en fragmentos: fragmentos para una historia", en Punto de vista 70, Buenos Aires.

Salas, Ernesto. 2006. La resistencia peronista. La toma del Frigorifico Lisandro de la Torre ,Buenos Aires, Altamira (1993).

Sarlo, Beatriz. 2000. La batalla de las ideas, 1943-1973, Buenos Aires, Ariel.

Sigal, Silvia. 1991. Intelectuales y poder en la década del sesenta, Buenos Aires, Puntosur.

y Eliseo Verón. 1984. Perón o muerte. Los fundamentos discursivos del fenómeno peronista, Buenos Aires, Hyspamérica.

Smulovitz, Catalina. 1988. Oposición y gobierno: los años de Frondizi, Buenos Aires, Centro Editor de América Latina, (2 volúmenes).

Spinelli, María Estela. 2007. "Historiografía política argentina. Explicación y comprensión en el análisis de la segunda mitad del siglo XX", en Anuario 7 Centro de Estudios Históricos “Profesor Carlos S. A Segreti”, Córdoba.

2008. "La impronta de la 'transición democrática' en la historiografía de la segunda mitad del siglo XX", en Estudios Filosofía Práctica e Historia de las Ideas, Revista anual de la Unidad de Historiografía e Historia de las Ideas, INCIHUSA, 
Spinelli. Las tendencias más recientes en la historiografía política argentina.

CONICET, Mendoza.

2005. Los vencedores vencidos. El antiperonismo y la "revolución libertadora (1955-1958), Buenos Aires, Biblos.

Szusterman, Celia. 1998. Frondizi. La política del desconcierto, Buenos Aires, Emecé.

Tcach, César. 1991. Sabattinismo y peronismo. Partidos políticos en Córdoba, 1943-1955, Buenos Aires, Editorial Sudamericana.

y Celso Rodríguez. 2006. Arturo Illia: un sueño breve. El rol del peronismo y de los Estados Unidos en el golpe militar de 1966, Buenos Aires, Edhasa.

Terán, Oscar. 1991. Nuestros años sesenta, Buenos Aires, Puntosur.

Torre, Juan Carlos. 1991. La vieja guardia sindical y Perón, Buenos Aires, Sudamericana. 1983. Los sindicatos en el gobierno, 1973-1976, Buenos Aires, CEAL.

Tortti, María Cristina. 2009. El viejo Partido Socialista y los orígenes de la nueva izquierda, (1955-1965), Buenos Aires, Prometeo.

Waldman Peter y Ernesto Garzón Valdés. 1983. El poder militar en la Argentina, Buenos Aires, Galerna.

Zanca, Eduardo. 2006. Los intelectuales católicos y el fin de la cristiandad, 1955-1966, Buenos Aires, Fondo de Cultura Económica.

Zanatta, Loris. 1996. Del Estado liberal a la Nación Católica, Bernal, Universidad de Quilmes. 2000. Perón y el mito de la Nación Católica, Buenos Aires, Sudamericana. 